\title{
Building an Intelligent Hydroinformatics Integration Platform for Regional Flood Inundation Warning Systems
}

\author{
Li-Chiu Chang ${ }^{1, *}$, Fi-John Chang ${ }^{2}$ (D), Shun-Nien Yang ${ }^{1}$, I-Feng Kao ${ }^{2}$, Ying-Yu Ku ${ }^{1}$, \\ Chun-Ling Kuo ${ }^{3}$ and Ir. Mohd Zaki bin Mat Amin ${ }^{4}$ \\ 1 Department of Water Resources and Environmental Engineering, Tamkang University, \\ New Taipei City 25137, Taiwan; aa22814946@yahoo.com.tw (S.-N.Y.); kuyingyu526@gmail.com (Y.-Y.K.) \\ 2 Department of Bioenvironmental Systems Engineering, National Taiwan University, Taipei 10617, Taiwan; \\ changfj@ntu.edu.tw (F.-J.C.); d05622002@ntu.edu.tw (I.-F.K.) \\ 3 Water Resources Agency, Ministry of Economic Affairs, Taipei 10617, Taiwan; a680010@wra.gov.tw \\ 4 Water Resources and Climatic Change Research Centre, National Hydraulic Research Institute of Malaysia, \\ 43300 Selangor, Malaysia; zaki@nahrim.gov.my \\ * Corresponding author: changlc@mail.tku.edu.tw; Tel.: +886-2-26258523
}

Received: 30 November 2018; Accepted: 19 December 2018; Published: 21 December 2018

\begin{abstract}
Flood disasters have had a great impact on city development. Early flood warning systems (EFWS) are promising countermeasures against flood hazards and losses. Machine learning (ML) is the kernel for building a satisfactory EFWS. This paper first summarizes the ML methods proposed in this special issue for flood forecasts and their significant advantages. Then, it develops an intelligent hydroinformatics integration platform (IHIP) to derive a user-friendly web interface system through the state-of-the-art machine learning, visualization and system developing techniques for improving online forecast capability and flood risk management. The holistic framework of the IHIP includes five layers (data access, data integration, servicer, functional subsystem, and end-user application) and one database for effectively dealing with flood disasters. The IHIP provides real-time flood-related data, such as rainfall and multi-step-ahead regional flood inundation maps. The interface of Google Maps fused into the IHIP significantly removes the obstacles for users to access this system, helps communities in making better-informed decisions about the occurrence of floods, and alerts communities in advance. The IHIP has been implemented in the Tainan City of Taiwan as the study case. The modular design and adaptive structure of the IHIP could be applied with similar efforts to other cities of interest for assisting the authorities in flood risk management.
\end{abstract}

Keywords: machine learning; early flood warning systems; hydroinformatics; database; flood forecast; Google Maps

\section{Introduction}

The degree and scale of flood hazards have increased massively with the changing climate in the last decades, and large-scale flash floods bring fast-moving and rapid-rising water with force, resulting in tremendous life and property losses as well as social disruption worldwide. Building resilience to natural disasters is one of the most pressing challenges for achieving sustainable urban development in flood-prone regions. Early flood warning systems (EFWS) are promising countermeasures against flood hazards and losses. The core of a satisfactory EFWS is the capability of sequentially providing a reliable and accurate forecast of the regional flood inundation depths with sufficient lead time. Machine Learning (ML) technologies have boosted mess applications because of its great flexibility and scalability in extracting significant features from complex data structures and providing better 
performance and cost-effective solutions. Its popularity dramatically increased among hydrologists. This special issue collects 18 original contributions addressing the state of the art of machine-learning methods, conducting a high level of research and providing practical information on how to implement ML methods for flood forecast along with case studies from different regions of the world. The selected manuscripts presented in this special issue provide more insights into machine-learning methods and strategies for accurate flood forecast. Contributions cover a wide range of topics, including:

1. The application of various ML methods with genetic algorithms and/or particle swarm optimization methods for flood hydrograph predictions [1,2];

2. Improved Ensemble Various Artificial Neural Networks (ANNs) for hydrological series extension and monthly streamflow forecasting [3-5];

3. Development of methodology for improving extreme learning machine method [6], random forest algorithm [7] and adaptive neuro-fuzzy inference system (ANFIS) with optimization algorithms for the forecast [8];

4. Improving the Muskingum Routing method using various optimization methods such as hybrid bat-swarm algorithm [9], improved bat algorithm [10], and Wolf Pack Algorithm [11], or combined with a particle filter-based assimilation model [12] for streamflow forecasts;

5. Using hybrid neural network models (self-organizing map and back-propagation neural networks) to model the rainfall-runoff process for flood forecasts [13];

6. Using Deep Learning (DL), convolutional neural network (CNN), for extracting urban water bodies based on remote-sensing imagery [14], and Long Short-Term Memory Network (LSTM) for the Dongting Lake water level forecast [15] and rainfall-runoff Simulation [16];

7. Building ANN-based methods-the self-organizing map (SOM) and recurrent nonlinear autoregressive with exogenous inputs (RNARX) to sequentially forecast area-wide inundation depths shown on Google Earth [17];

8. Providing an extensive overview of the various ML algorithms used in flood prediction and introducing the most promising prediction methods for both long-term and short-term floods [18].

Information systems play an important role in environmental and geoscience disciplines by providing integrated multi-disciplinary platforms that combine data management, visualization, analysis, modeling, and information communication capabilities. Recently, there has been growing interest in building flood early warning systems (FEWS) for extreme storms in an urban city. This has illustrated the increasing deployment of FEWS due to advances in ensemble weather forecasting, the availability of high-resolution satellite data, and artificial intelligence techniques as well as improved technology for communication and sharing of information. Among the most widely-used tools for online presentation of flood inundation maps with the effectiveness of possible countermeasures, FEWS are now regarded as cost-efficient alternatives to life-saving, damage prevention and the resilience enhancement of a society [19-22]. The provision of flood inundation maps regarding the extents and severity degrees of flood impacts plays a vital role in FEWS, and these maps provide a fundamental building block of ready-to-access content so that decisions can be made upon them. Given sufficient notice in a clear and informative manner, disaster damages can be mitigated considerably. Real-time access, analytical processing, and interactive visualizations are crucial to deliver a better understanding of flood-related issues [23]. Traditional systems that share flood-related data and information, however, have limited capabilities of integrating distributed data as well as visualizing and communicating modeling results. Recent advances in science and technology, especially computer-based data processing capabilities and communication facilities, have enabled longer lead times many steps ahead of flood forecasts along transboundary river basins. Developing early warning systems for the riparian countries can contribute to the mitigation of flood risks and life-saving through effective utilization of these new tools.

Over the last decades, many efforts have been devoted to flood defense strategies, which have focused mainly on non-structural efforts such as flood alerts and warning systems based on flood-depth forecasts [24-26]. Advances in computational techniques and the emergence of new data sources have 
provided hydrologists with tools to make management decisions on flood forecasting and flood risk management. Following this track, hydroinformatics has emerged as an essential tool by combining science, technologies and social considerations into a holistic coherent framework to timely deal with collecting, modeling, visualizing, and sharing flood-related information and to improve the applicability and accuracy of flood warnings [27-34]. ML methods are efficient tools for extracting the key information from complex highly dimensional input-output patterns and are widely used in various hydrological problems such as flood forecasts in this special issue [1-18] as well as groundwater and water management issues [35-46]. Recently, technological advances in social media have improved data gathering and dissemination, especially under the development of world-wide-web technologies. The Internet of Things (IoT) is a system of devices that collect data in real time and transfer it through a wireless network to a communication framework of control centers for analyzing the data and providing suitable countermeasures. Recent studies have indicated that the combination of IoT and machine-learning techniques could be beneficial to flood prediction $[47,48]$. Geographical information systems (GIS) are a user-friendly interface designed to access geographical services such as viewing, understanding, enquiring, interpreting and visualizing data [49-52]. The Google Maps Application Programming Interface (API) provides a programming application interface to integrate Google Maps into websites. A flood forecasting and warning system upon Google Maps can provide relevant meteorological and hydrological information of an event at critical timings, along with operational actions, results, impacts, and lessons learned. Recently, a spatial decision support system incorporated with wireless sensor networks and volunteered geographic information sources has been deployed in the town of São Carlos in Brazil, which has made flood risk management more effective [23]. Based on an ontology-based approach linking environmental models with disaster-related data, a flood disaster management system was explored to offer one-stop flood disaster management, and a subsequent $3 \mathrm{D}$ visualization was provided to improve the interpretability of disaster data and the effectiveness of decision-making processes [53]. Effective flood risk management requires updated information to ensure that the correct decisions can be made and that sufficiently accurate forecasts can be provided to promote community confidence so that the community will respond adequately when receiving warnings. The main challenge is to accurately forecast river flow in near real-time and to timely forecast flood peaks for drainage basins using the same technology.

This study aims to develop a user-friendly real-time regional flood forecasting system based on the state-of-the-art data-mining, visualization and system developing techniques such that actions can be efficiently taken to alleviate flood risks endangering residents and properties in inundation prone regions. We present a comprehensive flood warning platform, the intelligent hydroinformatics integration platform (IHIP), that could integrate data, analysis, module, and visualization to provide real-time Google-maps-based information of forecasted flood depths for urban areas in the Tainan City of Taiwan. The web tools and emerging web technologies used in the IHIP system that access rainfall, flood-related data, real-time flood forecasts, flood inundation maps, and interactive visualizations are introduced in the next section. This is followed by the implementation efforts and the description of the Google-maps-based flood depths information system in the study regions. The final section concludes the findings of this study and recommends future work enabled by the implementation of this system.

\section{System}

The purpose of this study is to provide a one-stop web-platform to visualize flood-related data and online regional flood inundation maps. As the main stakeholders of the web-platform are the public and authoritative officers, it is required to provide an interactive and user-friendly interface that requires minimal technical skills to use and to directly handle the visualization and examination of data within the platform, without external application. To achieve this goal, we develop an intelligent hydroinformatics integrated platform (IHIP) that not only implements the latest scientific technologies such as data acquisition, data assimilation and ML modeling for improving forecast capabilities but 
also organizes these issues in an integrative manner. The IHIP involves the processes of defining the components, modules, interfaces, and data for a system to satisfy specified requirements. We further develop the online display of flood inundation maps through a friendly web interface to visualize regional flood depths and interact with users. The framework is established based on the architecture that consists of five layers: data access layer; data integration layer; service layer; functional subsystem layer; and end-user application layer (Figure 1). Their main functions are described as follows.

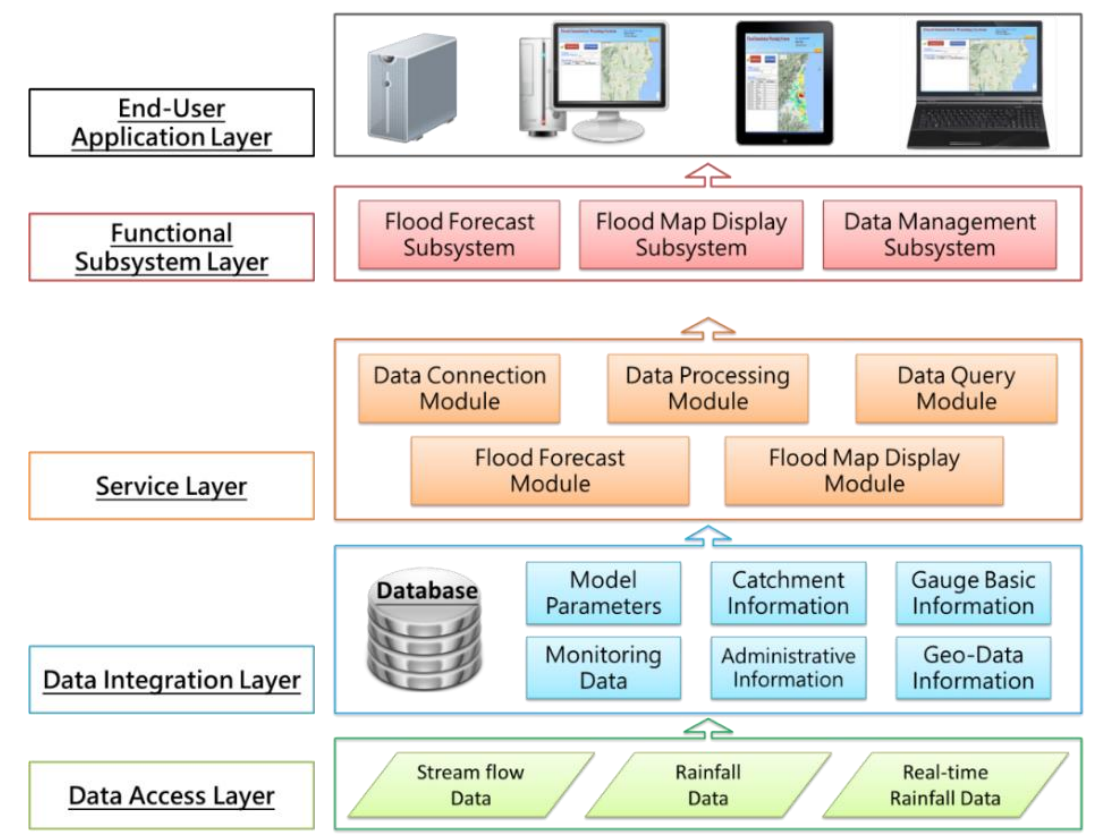

Figure 1. Architecture of the flood early warning system for river basins.

The data access layer provides simplified accesses to the real-time data of the web-database and automatically stores them in the persistent storage of the database. The data integration layer is a relational database and defines data relations which persistently store real-time data, model parameters, as well as the information of catchments, administrative divisions, gauges, and geo-data.

The service layer involves five modules (i.e., data collection, data processing, data query, flood forecast, and flood map display), manages the connections between the modules and database to ensure the effective communication among different layers, and implements the user interface of the end-user application layer.

The functional subsystem layer integrates subsystems of flood forecasting, flood map display, and data management not only to perform an important task or specific feature but also to display flood maps derived from the results of flood forecast models.

The end-user application layer is a rich web application interface that handles user interaction and navigation of the data and resources, and it also provides full end-user access to flood forecast results with a visualized geographic map-based website.

The data management, analysis, modeling and visualization of the IHIP provides the core functions of the system, in which the access to data and services from distributed sources is through the use of web services and application interfaces. The IHIP aims at improving the reliability and accuracy of flood forecasts and alleviating the burden imposed on the web server that handles all data queries, data visualization, and data analysis. The next sections will outline the modules, database and data acquisition used in the IHIP in details. 


\subsection{Modules}

To integrate the interactions and interchanges among layers and subsystems in the IHIP, several modules are designed. Modular Programming is a technique used to divide the functionality of a program into several independent and interchangeable modules, where each module executes only one aspect of the desired functionality. For interpreting the system, we use the term "module" to separate the independent functions and to explain the interactions and interchanges among modules and subsystems. Here, a module means an object with specific functions supporting different sub-systems when a sub-system interacts with the other part of the whole system. Different sub-systems may require the same functions so that the modules can provide specific and independent functions. This encapsulation is beneficial to the system, for instance, improving maintainability, reducing the impact of a change in data sources on the system, and allowing new data sources to be included in a flexible way. The relationships between four servers (i.e., web, model, database, real-time data), six modules and three sub-systems are shown in Figure 2. The six modules (i.e., Data Connection, Data Query, Data processing, Flood Forecast, Flood Map Display, and Web Server) are explained in more details as follows.

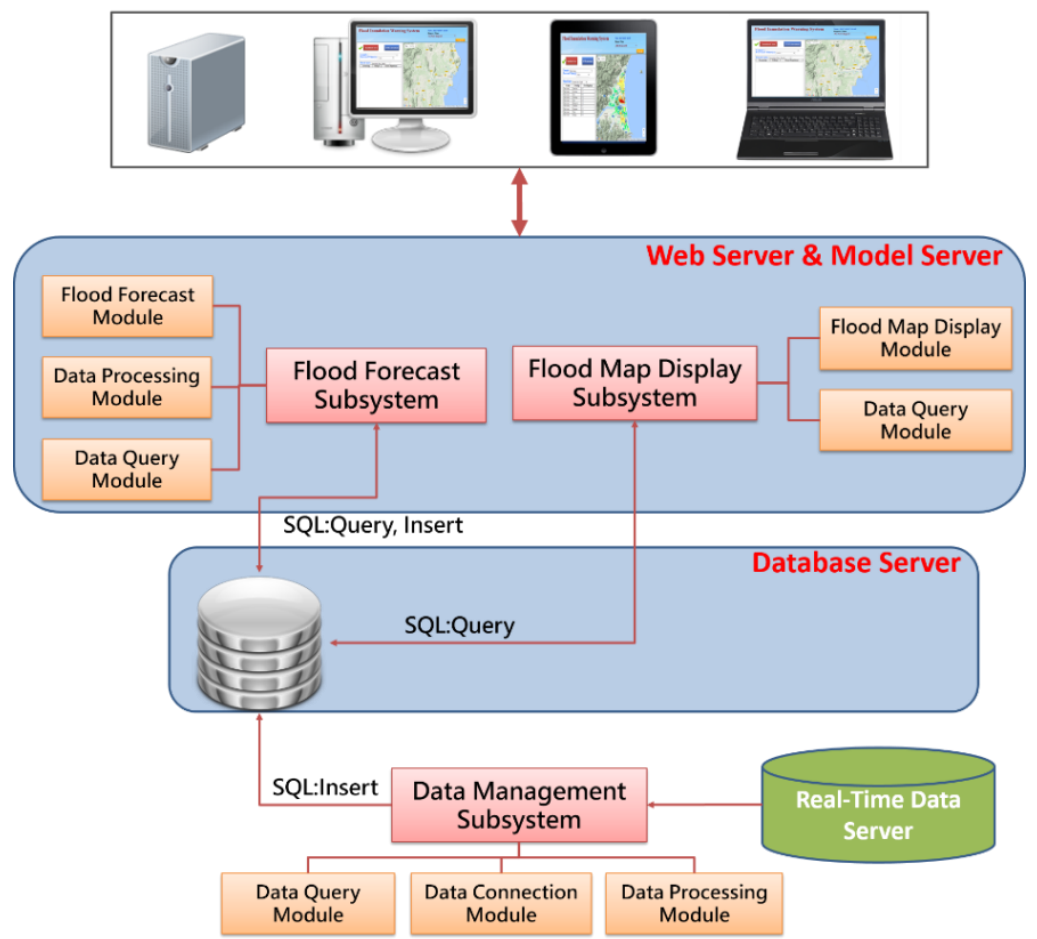

Figure 2. Relationships between four servers, five modules and three sub-systems.

Data Connection Module: This module builds connections between any kinds of databases, such as Microsoft SQL (Structured Query Language) Server or My SQL. It can build the connection between the system and the database management system, subject to user demands.

Data Query Module: This module assists data operators in accessing the Flood Forecast database for information such as query data, store data and forecasted flood data, and to acquire model parameters for building flood forecast models.

Data Processing Module: This module conducts data pre-processing, including normalization, transformation, inverse normalization, and missing data treatment.

Flood Forecast Module: This module implements a hybrid data-driven model (i.e., the recurrent nonlinear autoregressive with exogenous inputs (RNARX) and the self-organizing map (SOM)) to build the regional flood inundation forecast model, where those models require automatic execution with forecast results stored into the database of the flood forecasting system. 
Flood Map Display Module: The Google Maps API of the Google Maps Server Module is used to embed Google Maps into our website, on which site-specific data can be overlaid.

Web Server Module: This study focuses on online displaying and organizing regional flood inundation data using up-to-date web technologies driven by the database. Ajax (Asynchronous JavaScript and XML) is a growing web development technique for creating interactive web applications $[54,55]$ and is used in this proposed system. The Web Server Module can also automatically generate the Keyhole Markup Language (KML) files for download purpose. The generated KML files containing placemarks, polygons and textual descriptions can be displayed in Google Earth, ESRI ArcGIS Explorer, Adobe PhotoShop, AutoCAD, and Yahoo Pipes.

\subsection{Database and Data Acquisition}

\subsubsection{Database}

The significant global impact of recurring flooding events on hazard management leads to an increasing demand for comprehensive flood databases. Besides the programming for those modules and servers in the IHIP, a database is a vital part of organizing data and information for building forecasting models, maintaining the relations of the forecasted points, displaying the forecasted results, and managing the models. The relational database is one of the kernel parts for building a real-time visual map-based flood forecast system. This database can be divided into four parts: user management, hydrologic data, model information, and spatial data, respectively, which are explained in more detail as follows.

The user management part maintains the different roles of users, composed of username, password, and authorization. Authorization specifies the access rights to resources related to information security, computer security, and access control. During operation, the system uses these access control rules to decide whether access requests shall be granted or rejected.

The hydrologic data part maintains real-time hydrologic data composed of gauge information and observed gauge data. Real-time rainfall and streamflow data of each gauge have to be stored in this database.

The model information part includes catchment information and model parameters required for re-constructing and re-executing the flood forecast models.

The spatial data part includes administrative division information and geo-data information and provides the information required for flood map display. It provides the forecast models with inputs, maintains the parameters of these forecast models and their relationship, and offers the web-based map display with the geo-data and forecasted flood depths.

Database relationships are defined among real-time data, flood forecast models of different river basins, and geo-data for the map-based flood forecast display.

\subsubsection{Data Acquisition}

One of the most important tasks of the data access layer is to access real-time data because real-time data are the key inputs of the flood forecast models. The Quantitative Precipitation Estimation and Segregation Using Multiple Sensors (QPESUMS) use the Doppler radar, satellite infrared, rain gauge and other data sources to make the Quantitative Precipitation Estimations (QPE) for severe weather systems in Taiwan $[56,57]$. The Products of QPESUMS are presented in web page format which can be acquired online through retrieving spatial rainfall data when a typhoon (or heavy storm) strikes Taiwan. They are used in the case study of the Tainan City in Taiwan. All programs and related databases are constructed in Microsoft SQL Server 2016, where Visual C\# is used to develop four major items: (1) extracting real-time hydrological data; (2) managing real-time data relevant to the models; (3) storing the forecasted data; and (4) providing the information to the visual map-based display. 


\section{System Implementation}

With the support from the IHIP, administrators can activate the flood forecast module to obtain real-time multi-step-ahead flood forecasts. The IHIP would integrate the data management module and the forecast module. The forecast module would build the flood forecasting models based on model types and their parameters stored in the flood forecasting system database in the beginning. The data management module would periodically query rainfall data to feed into those flood forecasting models. Then, the forecasting models would periodically compute flood depths, and the forecast module would store these results in the flood forecasting system database. Flood depths are subsequently extracted and integrated with rainfall data for every place in the investigative area at a preset time interval, such as $1 \mathrm{~h}$, during flood events. Users visit the constructed website and choose a specific county to browse the flood forecasting results on Google Maps, with several display levels and zoom levels of Google Maps through the web server module and Google Maps server module services.

The combined application of the GIS and hydrological modeling determines flood extents and analyzes the role of the existing system. The ArcMap 10.0 (ArcGIS) software of the Environmental Systems Research Institute (ESRI) is set for the main operations with the geographical data of the case study area. The necessity of ArcMap 10.0 is high when developing the geometry of the area for further 1D steady flow simulation. For this purpose, the HEC-GeoRAS for ArcMap 10.0 extension is used, whereas the hydraulic modeling and calculations are set to be implemented in the river analysis system software, HEC-RAS (Hydrologic Engineering Center's River Analysis System), which is the product of US Army Corps of Engineers.

\subsection{Study Area}

The proposed IHIP system is implemented in the Tainan City of southern Taiwan. Tainan is the oldest city in Taiwan and is known for its history, temples, traditional lifestyles, and traditional snack food. Tainan has a subtropical climate with an annual average rainfall of $2500 \mathrm{~mm}$. The city enjoys a mild and dry climate in winter while rains take place more frequently in summer. Summer is the typhoon season here. Typhoons usually occur between June and November, with the highest number of weather watches coming in August and September. Tainan City has a high population density and is frequently affected by floods. Because of this, flood risk management research on the river catchments in the city is carried out in this study area.

\subsection{Online Display}

The web server deals merely with sending requests and responses between clients and the IHIP. We design a web page to display the real-time flood inundation forecasting results. The online system display embeds Google Maps in the web page of this flood warning system and provides KMZ (zipped Keyhole Markup Language, for used in Google Earth) files for download purpose. We create the ASP. NET Web application using C\# and access data from SQL server using ADO.NET. Considering the diversity of browsers and devices, we adopt the Responsive Web Design (RWD) and choose the layout with three different parts (header, main and footer) of a web page to make our website perform well and look great on any device such as desktops and smartphones.

The online regional flood inundation forecast model can convert a great number of grids' flood depths into regional inundation maps in GIF format and KML format, and thus, the server sends the related files to users without accessing the database. This also enhances server security, reduces the amount of data transmission, makes the website management and maintenance easy, and shortens the waiting time for loading a web page.

Figure 3 shows a web frame of the real-time flood warning system for Tainan City, which consists of three parts: header; main page and footer. The header includes the title of the system, the legend and the KMZ download button for displaying the forecasted results on Google Earth in user devices. The system title and two drop-down lists for years and date times are also displayed. The main page 
is divided into two parts. The left part includes time of issue, lead time, tree views of boundary and administration for displaying the forecasted results on Google Maps; the remaining space is divided into two sub-parts: control panel and Google Maps. In the control panel, users can access different forecast times, inundated areas, forecast lead times, or read different flood information by selecting an option listed in the drop-down menu. The legend of the flood inundation level is shown in the upper left corner. Here, we provide the quadratic-color flood warning system that shows warning levels (coded by severity) in green, blue, yellow, and red colors such that users can easily visualize (recognize) the inundating depths (conditions) in the whole area. A green warning means level 1 (the least severe) with flood depths ranging from 0.3 to $0.9 \mathrm{~m}$; a blue warning means level 2 with flood depths ranging from 0.9 to $1.5 \mathrm{~m}$; a yellow warning means level 3 with flood depths ranging from 1.5 to $2.5 \mathrm{~m}$; and a red warning means level 4 (the most severe) with flood depths above $2.5 \mathrm{~m}$.

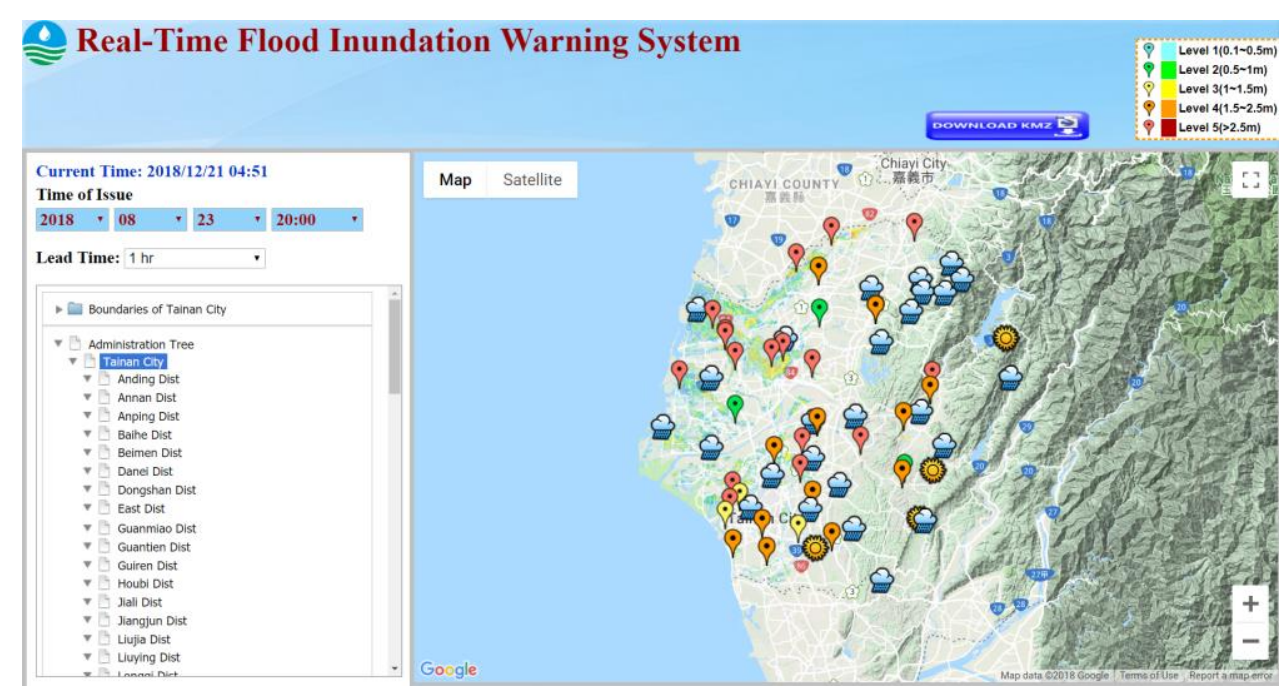

Figure 3. A web frame of the real-time flood warning system for Tainan City.

For the right part, click the toggle button of the inundated area to display this area in Google Maps; click the KML download button to download the flood forecast file in KML format; use the forecast time drop-down menu to display the forecasted results at different times; use the drop-down menu to select the administrative area; and use the flood location information drop-down menu to provide the flood depths in a variety of important locations. In the Footer, there are organization logos and copyright information for this online display web page.

Figure 4 shows the presentation screen of the system on the display interface. Figure 4 a selects the administrative area (Districts, Villages of the Tainan City); Figure $4 \mathrm{~b}$ provides the flood depths in selected villages and Figure $4 \mathrm{c}$ displays the rainfall and the maximal flood inundation depths of the selected gauges on Google Maps. 


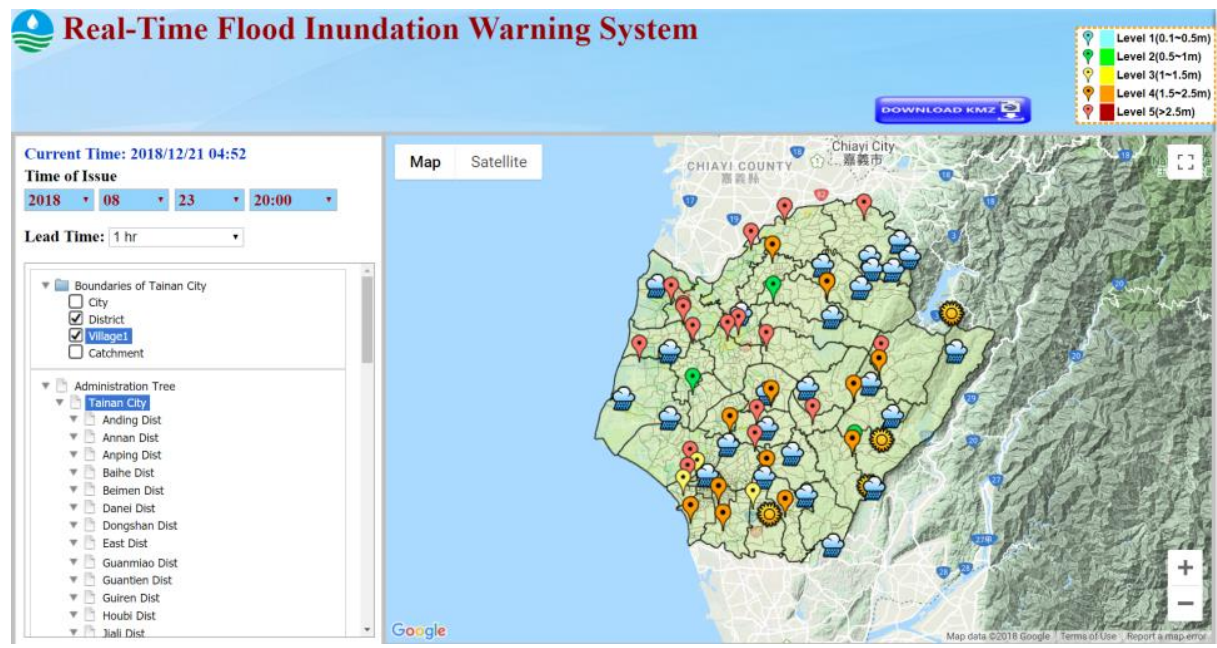

(a)

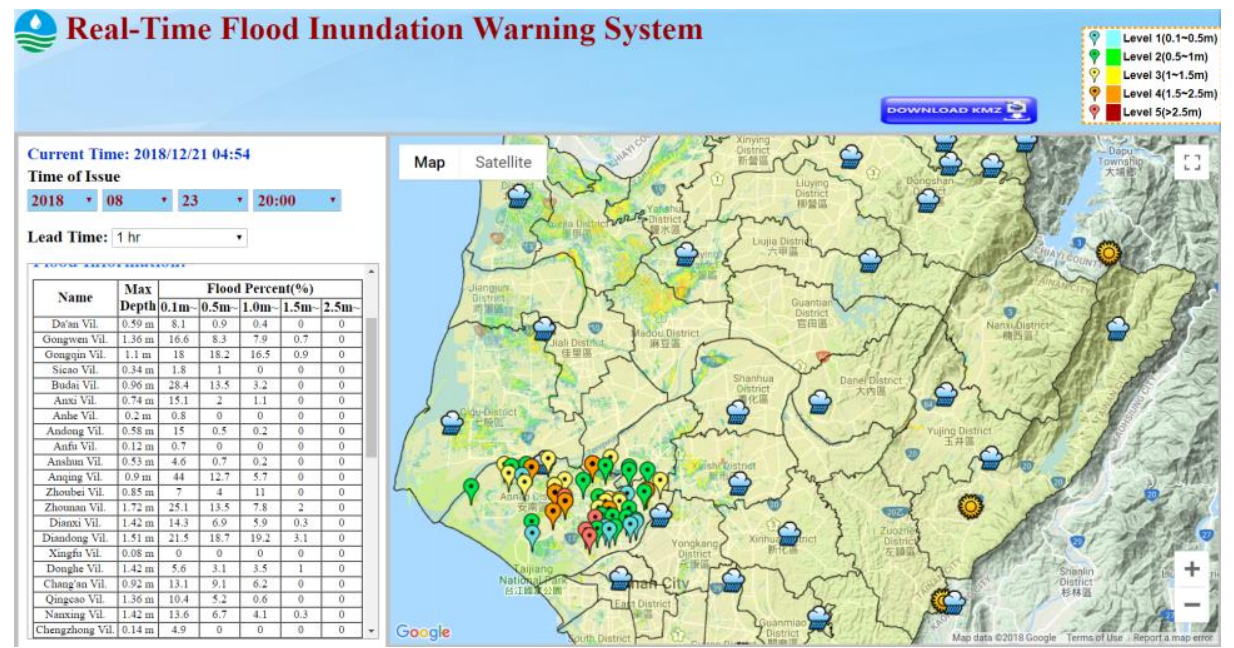

(b)

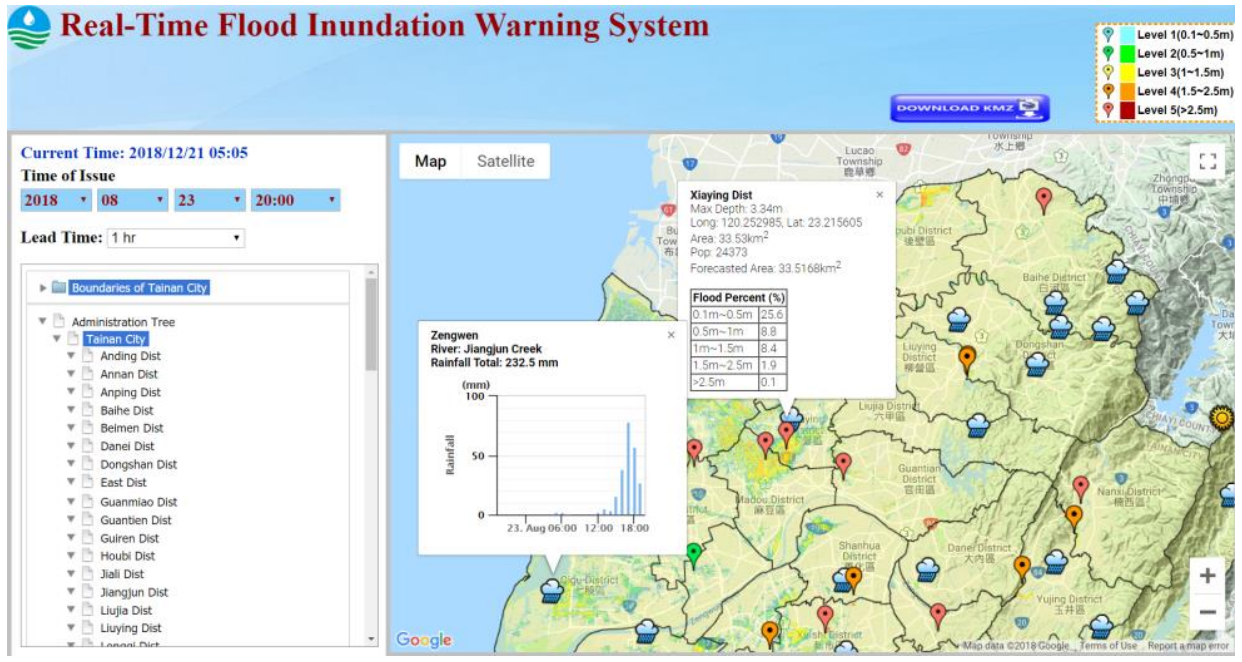

(c)

Figure 4. Main functions of the display interface. (a) Districts, Villages; (b) Table of flood information in selected villages; (c) Rainfall information and the maximal flood inundation depths display on Google Map. 
First of all, users can choose the forecast time through the Report Time menu in the top right corner, which is presented by the year, month, date, and hour (ex., 2018/08/23, 20:00), as shown in Figure 4. After time selection, the system will fill in the forecast area, time interval, inundation information, and others. As shown, the maximum inundation depth of each selected village will be tabulated at the bottom left of the interface, and its location will be marked on the map simultaneously. Furthermore, when clicking the Legend icon at the top of the screen, it will display the illustrations of different colors or makers on the map. At last, the KMZ file can be downloaded by clicking the KML download button on Google Earth.

The IHIP allows the monitoring of flooding in a community or a larger region within a single interface and thus, reduces the dependence on tracking multiple sources of information. Second, real-time data from stream gauges and flood forecasting models helps decision-makers and the public take necessary actions to prepare for flood events. Third, the support for multiple devices allows users to access data and information anywhere, and web service availability makes data within the IHIP accessible from other information systems and applications. The IHIP offers a comprehensive information system for improving real-time information management and knowledge transfer pertinent to flood events.

\section{Conclusions}

A flood early warning system enables an advanced warning of probable flash floods and regional inundation depths for disseminating alarms in flood-threatened areas. A real-time flood inundation map can convey a strong message about the extents and severity degrees of flooding in inundation-prone regions, together with the effectiveness of possible countermeasures. We develop an intelligent hydroinformatics integration platform (IHIP) to provide online forecasting of regional flood depths through the use of the latest hydroinformatics technologies such that actions can be efficiently taken to mitigate flood risks. The holist framework of the IHIP coupled with the coherent sub-systems, modules, database, and interfaces are introduced. We construct the database and data acquisition under the Microsoft Windows Operating System platform. A web interface is designed to display the forecasts of flood inundation depths in the study areas using the up-to-date web technologies driven by the database. The established flood inundation maps can visualize the potential effects of flooding and communicate scenario development with all stakeholders. The IHIP can be easily executed through the database to simultaneously access the datasets and update the parameters and information obtained from model outputs. The system can very quickly (in just a few seconds) carry out multi-step-ahead forecasts of area-wide inundation maps and thereby lead to real-time flood forecasting. A quadratic-color flood inundation map showing inundated levels in different colors in Google Maps can help users to easily visualize (identify) the threats and impacts of floods on the whole area.

The IHIP is designed in an adaptive and integrated structure that can integrate information from distributed sources and allows an easy development of similar systems for other regionals through knowledge transfer. This system can disseminate flood-related data and information to the public such as forecast flood occurrence and alert communities in advance for reducing flood damages.

Author Contributions: Conceptualization and Methodology, L.-C.C. and F.-J.C.; Software, L.-C.C., S.-N.Y., I.-F.K., Analysis, L.-C.C., S.-N.Y., Y.-Y.K.; Resources, C.-L.K. and Ir. M.Z. bin M.A.; Writing-Review \& Editing, L.-C.C. and F.-J.C.

Funding: This research was funded by the Water Resources Agency, Ministry of Economic Affairs, Taiwan, R.O.C. (Grant number: MOEAWRA1070095).

Acknowledgments: The authors gratefully acknowledge the Water Resources Agency, Taiwan for supporting this study. Simulated flood inundation datasets provided by the NCKU Research and Devolopment Fundation and the National Center for High-performance Computing are greatly appreciated. The authors of this editorial and Guest Editor of this special issue would like to thank all authors for their notable contributions to this special issue, the reviewers for devoting their efforts to reviewing the manuscripts, and the Water Editorial team for their great support during the review of the submitted manuscripts.

Conflicts of Interest: The authors declare no conflict of interest. 


\section{References}

1. Tayfur, G.; Singh, V.; Moramarco, T.; Barbetta, S. Flood hydrograph prediction using machine learning methods. Water 2018, 10, 968. [CrossRef]

2. Jabbari, A.; Bae, D.H. Application of Artificial Neural Networks for Accuracy Enhancements of Real-Time Flood Forecasting in the Imjin Basin. Water 2018, 10, 1626. [CrossRef]

3. Yu, Y.; Zhang, H.; Singh, V.P. Forward prediction of runoff data in data-scarce basins with an improved ensemble empirical mode decomposition (EEMD) model. Water 2018, 10, 388. [CrossRef]

4. Zhou, J.; Peng, T.; Zhang, C.; Sun, N. Data Pre-Analysis and Ensemble of Various Artificial Neural Networks for Monthly Streamflow Forecasting. Water 2018, 10, 628. [CrossRef]

5. Chiang, Y.M.; Hao, R.N.; Zhang, J.Q.; Lin, Y.T.; Tsai, W.P. Identifying the Sensitivity of Ensemble Streamflow Prediction by Artificial Intelligence. Water 2018, 10, 1341. [CrossRef]

6. Chen, L.; Sun, N.; Zhou, C.; Zhou, J.; Zhou, Y.; Zhang, J.; Zhou, Q. Flood Forecasting Based on an Improved Extreme Learning Machine Model Combined with the Backtracking Search Optimization Algorithm. Water 2018, 10, 1362. [CrossRef]

7. Muñoz, P.; Orellana-Alvear, J.; Willems, P.; Célleri, R. Flash-Flood Forecasting in an Andean Mountain Catchment-Development of a Step-Wise Methodology Based on the Random Forest Algorithm. Water 2018, 10, 1519. [CrossRef]

8. Tien Bui, D.; Khosravi, K.; Li, S.; Shahabi, H.; Panahi, M.; Singh, V.; Chapi, K.; Shirzadi, A.; Panahi, S.; Chen, W.; et al. New hybrids of anfis with several optimization algorithms for flood susceptibility modeling. Water 2018, 10, 1210. [CrossRef]

9. Ehteram, M.; Binti Othman, F.; Mundher Yaseen, Z.; Abdulmohsin Afan, H.; Falah Allawi, M.; Najah Ahmed, A.; Shahid, S.; P Singh, V.; El-Shafie, A. Improving the Muskingum flood routing method using a hybrid of particle swarm optimization and bat algorithm. Water 2018, 10, 807. [CrossRef]

10. Farzin, S.; Singh, V.; Karami, H.; Farahani, N.; Ehteram, M.; Kisi, O.; Allawi, M.; Mohd, N.; El-Shafie, A. Flood routing in river reaches using a three-parameter Muskingum model coupled with an improved bat algorithm. Water 2018, 10, 1130. [CrossRef]

11. Bai, T.; Wei, J.; Yang, W.; Huang, Q. Multi-Objective Parameter Estimation of Improved Muskingum Model by Wolf Pack Algorithm and Its Application in Upper Hanjiang River, China. Water 2018, 10, 1415. [CrossRef]

12. Chen, M.; Pang, J.; Wu, P. Flood Routing Model with Particle Filter-Based Data Assimilation for Flash Flood Forecasting in the Micro-Model of Lower Yellow River, China. Water 2018, 10, 1612. [CrossRef]

13. Jhong, Y.D.; Chen, C.S.; Lin, H.P.; Chen, S.T. Physical Hybrid Neural Network Model to Forecast Typhoon Floods. Water 2018, 10, 632. [CrossRef]

14. Chen, Y.; Fan, R.; Yang, X.; Wang, J.; Latif, A. Extraction of Urban Water Bodies from High-Resolution Remote-Sensing Imagery Using Deep Learning. Water 2018, 10, 585. [CrossRef]

15. Liang, C.; Li, H.; Lei, M.; Du, Q. Dongting Lake Water Level Forecast and Its Relationship with the Three Gorges Dam Based on a Long Short-Term Memory Network. Water 2018, 10, 1389. [CrossRef]

16. Hu, C.; Wu, Q.; Li, H.; Jian, S.; Li, N.; Lou, Z. Deep Learning with a Long Short-Term Memory Networks Approach for Rainfall-Runoff Simulation. Water 2018, 10, 1543. [CrossRef]

17. Chang, L.C.; Amin, M.; Yang, S.N.; Chang, F.J. Building ANN-Based Regional Multi-Step-Ahead Flood Inundation Forecast Models. Water 2018, 10, 1283. [CrossRef]

18. Mosavi, A.; Ozturk, P.; Chau, K.W. Flood Prediction Using Machine Learning Models: Literature Review. Water 2018, 10, 1536. [CrossRef]

19. Alfieri, L.; Thielen, J. A European precipitation index for extreme rain-storm and flash flood early warning. Meteorol. Appl. 2015, 22, 3-13. [CrossRef]

20. Pappenberger, F.; Cloke, H.L.; Parker, D.J.; Wetterhall, F.; Richardson, D.S.; Thielen, J. The monetary benefit of early flood warnings in Europe. Environ. Sci. Policy 2015, 51, 278-291. [CrossRef]

21. Cools, J.; Innocenti, D.; O’Brien, S. Lessons from flood early warning systems. Environ. Sci. Policy 2016, 58, 117-122. [CrossRef]

22. Girons Lopez, M.; Di Baldassarre, G.; Seibert, J. Impact of social preparedness on flood early warning systems. Water Resour. Res. 2017, 53, 522-534. [CrossRef] 
23. Horita, F.E.; de Albuquerque, J.P.; Degrossi, L.C.; Mendiondo, E.M.; Ueyama, J. Development of a spatial decision support system for flood risk management in Brazil that combines volunteered geographic information with wireless sensor networks. Comput. Geosci. 2015, 80, 84-94. [CrossRef]

24. Chan, N.W. Impacts of disasters and disaster risk management in Malaysia: The case of floods. In Resilience and Recovery in Asian Disasters; Springer: Tokyo, Japan, 2015; pp. 239-265.

25. Chang, L.C.; Shen, H.Y.; Chang, F.J. Regional flood inundation nowcast using hybrid SOM and dynamic neural networks. J. Hydrol. 2014, 519, 476-489. [CrossRef]

26. Chang, L.C.; Shen, H.Y.; Wang, Y.F.; Huang, J.Y.; Lin, Y.T. Clustering-based hybrid inundation model for forecasting flood inundation depths. J. Hydrol. 2010, 385, 257-268. [CrossRef]

27. Bogner, K.; Liechti, K.; Zappa, M. Error Correcting and Combining Multi-model Flood Forecasting Systems. In Advances in Hydroinformatics; Springer: Singapore, 2018; pp. 569-578.

28. Herrera, M.; Meniconi, S.; Alvisi, S.; Izquierdo, J. Advanced Hydroinformatic Techniques for the Simulation and Analysis of Water Supply and Distribution Systems; MDPI: Basel, Switzerland, 2018.

29. Lynggaard-Jensen, A.; Mark, O.; Gourbesville, P. ICT for urban water infrastructure. Available online: https:/ / www.researchgate.net/publication/295401876_ICT_for_urban_water_infrastructure (accessed on 19 December 2018).

30. Nguyen, P.; Thorstensen, A.; Sorooshian, S.; Hsu, K.; AghaKouchak, A. Flood forecasting and inundation mapping using HiResFlood-UCI and near-real-time satellite precipitation data: The 2008 Iowa flood. J. Hydrometeorol. 2015, 16, 1171-1183. [CrossRef]

31. Pinho, J.; Ferreira, R.; Vieira, L.; Schwanenberg, D. Comparison between two hydrodynamic models for flooding simulations at river Lima basin. Water Resour. Manag. 2015, 29, 431-444. [CrossRef]

32. Vojinovic, Z.; Abbott, M.B. Twenty-Five Years of Hydroinformatics. Water 2017, 9, 59. [CrossRef]

33. Wan, Z.; Hong, Y.; Khan, S.; Gourley, J.; Flamig, Z.; Kirschbaum, D.; Tang, G. A cloud-based global flood disaster community cyber-infrastructure: Development and demonstration. Environ. Model. Softw. 2014, 58, 86-94. [CrossRef]

34. Yan, K.; Di Baldassarre, G.; Solomatine, D.P.; Schumann, G.J.P. A review of low-cost space-borne data for flood modelling: Topography, flood extent and water level. Hydrol. Processes 2015, 29, 3368-3387. [CrossRef]

35. Antonopoulos, V.Z.; Gianniou, S.K.; Antonopoulos, A.V. Artificial neural networks and empirical equations to estimate daily evaporation: Application to lake Vegoritis, Greece. Hydrol. Sci. J. 2016, 61, 2590-2599. [CrossRef]

36. Atieh, M.; Taylor, G.; Sattar, A.M.; Gharabaghi, B. Prediction of flow duration curves for ungauged basins. J. Hydrol. 2017, 545, 383-394. [CrossRef]

37. Chang, L.C.; Chen, P.A.; Chang, F.J. Reinforced two-step-ahead weight adjustment technique for online training of recurrent neural networks. IEEE Trans. Neural Netw. Learn. Syst. 2012, 23, 1269-1278. [CrossRef]

38. Chang, F.J.; Chang, L.C.; Huang, C.W.; Kao, I.F. Prediction of monthly regional groundwater levels through hybrid soft-computing techniques. J. Hydrol. 2016, 541, 965-976. [CrossRef]

39. Chang, F.J.; Huang, C.W.; Cheng, S.T.; Chang, L.C. Conservation of groundwater from over-exploitationScientific analyses for groundwater resources management. Sci. Total Environ. 2017, 598, 828-838. [CrossRef]

40. Chang, F.J.; Tsai, M.J. A nonlinear spatio-temporal lumping of radar rainfall for modelling multi-step-ahead inflow forecasts by data-driven techniques. J. Hydrol. 2016, 30, 1395-1413.

41. Chen, I.T.; Chang, L.C.; Chang, F.J. Exploring the Spatio-Temporal Interrelation between Groundwater and Surface Water by Using the Self-Organizing Maps. J. Hydrol. 2018, 556, 131-142. [CrossRef]

42. Mohanty, S.; Jha, M.K.; Raul, S.K.; Panda, R.K.; Sudheer, K.P. Using artificial neural network approach for simultaneous forecasting of weekly groundwater levels at multiple sites. Water Resour. Manag. 2015, 29, 5521-5532. [CrossRef]

43. Pektas, A.O.; Cigizoglu, H.K. Investigating the extrapolation performance of neural network models in suspended sediment data. Hydrol. Sci. J. 2017, 62, 1694-1703. [CrossRef]

44. Shiri, J.; Marti, P.; Nazemi, A.H.; Sadraddini, A.A.; Kisi, O.; Landeras, G.; Fard, A.F. Local vs. external training of neuro-fuzzy and neural networks models for estimating reference evapotranspiration assessed through k-fold testing. Hydrol. Res. 2015, 46, 72-88. [CrossRef]

45. Wang, J.; Shi, P.; Jiang, P.; Hu, J.; Qu, S.; Chen, X.; Chen, Y.; Dai, Y.; Xiao, Z. Application of BP Neural Network Algorithm in Traditional Hydrological Model for Flood Forecasting. Water 2017, 9, 48. [CrossRef] 
46. Yaseen, Z.M.; Fu, M.; Wang, C.; Mohtar, W.H.M.W.; Deo, R.C.; El-shafie, A. Application of the Hybrid Artificial Neural Network Coupled with Rolling Mechanism and Grey Model Algorithms for Streamflow Forecasting Over Multiple Time Horizons. Water Resour. Manag. 2018, 32, 1883-1899. [CrossRef]

47. Balis, B.; Bubak, M.; Harezlak, D.; Nowakowski, P.; Pawlik, M.; Wilk, B. Towards an operational database for real-time environmental monitoring and early warning systems. Procedia Comput. Sci. 2017, 108, 2250-2259. [CrossRef]

48. Mitra, P.; Ray, R.; Chatterjee, R.; Basu, R.; Saha, P.; Raha, S.; Barman, R.; Patra, S.; Biswas, S.S.; Saha, S. Flood forecasting using Internet of things and artificial neural networks. In Proceedings of the 2016 IEEE 7th Annual Information Technology, Electronics and Mobile Communication Conference (IEMCON), Vancouver, BC, Canada, 13-15 October 2016; pp. 1-5.

49. Bonilla Valverde, J.P.; Blank, C.; Roidt, M.; Schneider, L.; Stefan, C. Application of a GIS Multi-Criteria Decision Analysis for the Identification of Intrinsic Suitable Sites in Costa Rica for the Application of Managed Aquifer Recharge (MAR) through Spreading Methods. Water 2016, 8, 391. [CrossRef]

50. Fernández, P.; Santana, J.; Sánchez, A.; Trujillo, A.; Domínguez, C.; Suárez, J.P. A GIS Water Management System Using Free and Open Source Software. In Ubiquitous Computing and Ambient Intelligence; Springer: Cham, Switzerland, 2016; pp. 383-394.

51. Şener, Ş.; Şener, E.; Davraz, A. Evaluation of water quality using water quality index (WQI) method and GIS in Aksu River (SW-Turkey). Sci. Total Environ. 2017, 584, 131-144. [CrossRef]

52. Tehrany, M.S.; Pradhan, B.; Jebur, M.N. Flood susceptibility mapping using a novel ensemble weights-ofevidence and support vector machine models in GIS. J. Hydrol. 2014, 512, 332-343. [CrossRef]

53. Qiu, L.; Du, Z.; Zhu, Q.; Fan, Y. An integrated flood management system based on linking environmental models and disaster-related data. Environ. Model. Softw. 2017, 91, 111-126. [CrossRef]

54. Garrett, J.J. Ajax: A New Approach to Web Applications. 2005. Available online: http:/ /www.adaptivepath. com/publications/essays/archives/000385 (accessed on 19 December 2018).

55. Mahemoff, M. AJAX Design Patterns: Creating Web 2.0 Sites with Programming and Usability patterns; O'Reilly Media, Inc.: Sebastopol, CA, USA, 2006.

56. Chiou, P.T.K.; Chen, C.R.; Chang, P.L.; Jian, G.J. Status and outlook of very short range forecasting system in Central Weather Bureau, Taiwan. In Applications with Weather Satellites II; International Society for Optics and Photonics: Bellingham, WA, USA, 2005; Volume 5658, pp. 185-197.

57. Chen, C.Y.; Lin, L.Y.; Yu, F.C.; Lee, C.S.; Tseng, C.C.; Wang, A.H.; Cheung, K.W. Improving debris flow monitoring in Taiwan by using high-resolution rainfall products from QPESUMS. Nat. Hazards 2007, 40, 447-461. [CrossRef]

(C) 2018 by the authors. Licensee MDPI, Basel, Switzerland. This article is an open access article distributed under the terms and conditions of the Creative Commons Attribution (CC BY) license (http:/ / creativecommons.org/licenses/by/4.0/). 